\title{
Global transcriptional analysis reveals surface remodeling of Anaplasma marginale in the tick vector
}

\author{
G Kenitra Hammac ${ }^{1,3}$, Sebastián Aguilar Pierlé ${ }^{1}$, Xiaoya Cheng ${ }^{1}$, Glen A Scoles ${ }^{2}$ and Kelly A Brayton ${ }^{1 *}$
}

\begin{abstract}
Background: Pathogens dependent upon vectors for transmission to new hosts undergo environment specific changes in gene transcription dependent on whether they are replicating in the vector or the mammalian host. Differential gene transcription, especially of potential vaccine candidates, is of interest in Anaplasma marginale, the tick-borne causative agent of bovine anaplasmosis.

Methods: RNA-seq technology allowed a comprehensive analysis of the transcriptional status of A. marginale genes in two conditions: bovine host blood and tick derived cell culture, a model for the tick vector. Quantitative PCR was used to assess transcription of a set of genes in A. marginale infected tick midguts and salivary glands at two time points during the transmission cycle.

Results: Genes belonging to fourteen pathways or component groups were found to be differentially transcribed in $A$. marginale in the bovine host versus the tick vector. One of the most significantly altered groups was composed of surface proteins. Of the 56 genes included in the surface protein group, eight were up regulated and 26 were down regulated. The down regulated surface protein encoding genes include several that are well studied due to their immunogenicity and function. Quantitative PCR of a set of genes demonstrated that transcription in tick cell culture most closely approximates transcription in salivary glands of recently infected ticks.

Conclusions: The ISE6 tick cell culture line is an acceptable model for early infection in tick salivary glands, and reveals disproportionate down regulation of surface protein genes in the tick. Transcriptional profiling in other cell lines may help us simulate additional microenvironments. Understanding vector-specific alteration of gene transcription, especially of surface protein encoding genes, may aid in the development of vaccines or transmission blocking therapies.
\end{abstract}

Keywords: Global transcription, Intracellular bacteria, RNA-seq, Transcriptomics, Surface proteins

\section{Background}

Pathogens dependent upon vectors for transmission to new hosts undergo environment specific changes in gene transcription dependent on whether they are replicating in the vector or the vertebrate host. This dynamic relationship has been investigated in several human pathogens. For example, transcriptional analysis of Ehrlichia chaffeensis, the causative agent of human monocytic ehrlichiosis, revealed increased transcriptional activity and

\footnotetext{
* Correspondence: kbrayton@vetmed.wsu.edu

'Program in Genomics, Department of Veterinary Microbiology and Pathology, Paul G. Allen School for Global Animal Health, Washington State University, Pullman, WA 99164-7040, USA

Full list of author information is available at the end of the article
}

expression levels in tick cells versus human cells [1]. There is an inverse relationship between the transcription levels of outer surface proteins (OSP) A and C of Borrelia burgdorferi, the causative agent of Lyme disease, indicative of mammalian host and vector specific protein expression $[2,3]$. Similarly, differential transcription of Anaplasma phagocytophilum genes between tick and human cell lines was disproportionately represented by membrane or surface proteins [4]. Vector-specific alteration of gene transcription sheds light onto the mechanisms that orchestrate the transition between mammalian host and vector, which is especially of interest in the context of surface protein-encoding genes as these molecules are potential 
targets for vaccine development or transmission blocking therapies.

We are interested in exploring differences in pathogen transcription in these dissimilar environments and are using Anaplasma marginale as our model. A. marginale is an obligate intracellular pathogen that causes bovine anaplasmosis and depends on a tick vector for efficient transmission. In the bovine host $A$. marginale infects the erythrocyte and replicates up to levels of $10^{9}$ bacteria per $\mathrm{ml}$ of blood. When ticks feed on infected cattle, $A$. marginale first invades and colonizes the midgut epithelium in a receptor mediated process involving the surface protein Msp1a [5-9]. Within the midgut epithelial cells, A. marginale replicates within intracellular vacuoles to form colonies of up to several hundred organisms per cell. After this initial replication in the midgut epithelium, A. marginale enters the hemolymph and subsequently invades the salivary gland epithelial cells $[6,10,11]$. Final replication of up to $10^{6}$ organisms per salivary gland pair and development of infectivity for cattle requires re-attachment and initiation of feeding followed by inoculation of $A$. marginale with the saliva into the susceptible host [10-12]. Thus, A. marginale transmission requires that it efficiently invades and replicates in tick tissues, culminating in the development of infectivity in the salivary gland. Because of the relevance of the pathogen-vector transition, much work has gone into examining changes the pathogen undergoes in these two different environments.

Because of technical challenges associated with tick rearing, infection and processing, cultured tick cells have been used as a model for the tick phase of the A. marginale life cycle. Specifically, continuous embryonic cell lines from Ixodes scapularis (ISE6 or IDE8) were used in this and previous studies $[13,14]$. Altered gene transcription and expression in A. marginale has been demonstrated between bovine erythrocytes and tissues of the tick vector or cultured tick cells by quantitative PCR, immunoblotting and comparative mass spectrometric analysis [15-19]. In addition to quantitative change, more structurally complex variants of $m s p 2$ have been shown to predominate in mammalian versus tick cell lines suggesting a functional purpose for the complexity of the variants [20].

High throughput sequencing technologies used to obtain information about a sample's RNA content, or RNA-seq, have proven to be reliable tools for determining whole genome transcriptional activity in many species including obligate intracellular bacteria [21-23]. In the present study, the power of RNA-seq was harnessed to study the transcriptional dynamics of $A$. marginale in tick cell culture and bovine erythrocytes. The power and reproducibility of this technique allowed for a more comprehensive analysis than has been possible with other methods. Comparison of transcript levels from organisms isolated from these two environments reveals modulation of 14 pathways or component groups, with surface protein genes showing the highest degree of modulation in the St. Maries strain of $A$. marginale between the bovine host and tick cell culture. These observations allowed us to test whether tick cell culture is a suitable model for the tick vector.

\section{Methods}

\section{Ethics statement}

Animal experiments were approved by the Institutional Animal Care and Use Committee at Washington State University, USA, in accordance with institutional guidelines based on the U.S. National Institutes of Health (NIH) Guide for the Care and Use of Laboratory Animals (ASAF 4440).

\section{Deep sequencing}

RNA was prepared from two biological replicates of A. marginale St. Maries strain maintained in ISE6 cell culture as previously described $[13,14,24]$ and two biological replicates from infected bovine blood [21]. Samples were collected and processed using TRIzol (Invitrogen, Carlsbad, CA, USA) for RNA extraction, the MICROBEnrich kit (Ambion, Austin, TX, USA) to negatively select eukaryotic RNA and were normalized using DuplexSpecific thermostable Nuclease (DSN) (Illumina, San Diego, CA, USA) $[21,25]$. Samples were sequenced with Illumina technology with 100 base pair reads [25]. The accession numbers for this RNA-seq study in the GenBank Sequence Read Archive (SRA) are SRP014580 and SRP014580.

\section{Comparative transcriptional analysis}

CLC Genomics Workbench 6.0.2 (CLC Bio, Cambridge, MA, USA) was used to process RNA-seq data. Expression levels of genes were normalized by both library size and gene length effects by use of the reads per kilobase of gene model per million mapped reads (RPKM) [26]. Transcriptional fold change was determined between two conditions: A. marginale in ISE6 cell culture and blood. For inclusion in the final analysis, normalized fold change calculations had a p-value of $<0.01$ according to Kal's Z-test [27]. Fold changes were considered significant for surface proteins if greater than two standard deviations above or below the average fold change across all genes between replicates. Briefly, when differential expression is defined as greater than two standard deviations from the mean, genes with fold changes greater or smaller than the calculated value can be classified as up- or down-regulated at a confidence level of approximately 95\% [28]. To determine if surface protein transcription differed between conditions as a group, a category was created including all surface exposed proteins encoded by a single gene and was compared to previously established categories by gene set enrichment 
analysis (GSEA) [25,29]. Significantly altered categories or pathways were considered at $\mathrm{p}<0.05$.

\section{K-means clustering}

The mean transcriptional value of each gene to the cluster whose center is nearest was assigned using K-means clustering. This procedure was applied to Illumina data in order to assess the general behavior of the putative protein surface encoding genes. Lloyd's algorithm was used for these experiments [30]. Euclidean distance was used as distance metric; four partitions were used to generate the clusters. For each gene, the mean gene expression value over all input samples was subtracted. Normalized expression values were used for clustering. Once gene clusters were generated, seven surface encoding genes present in Cluster 3 and three genes present in Cluster 1 were chosen for qRT-PCR validation of Illumina data. Silhouette Indices [31] were calculated for these genes to verify that they accurately represent their Cluster and its transcriptional behavior, and therefore are adequate for RNA-seq data validation.

\section{Tick samples}

Male Dermacentor andersoni ticks of the Reynolds Creek stock that have been demonstrated to efficiently transmit A. marginale St. Maries were used in this experiment [32,33]. Naïve 5 month old calf 40420 was injected intravenously with $A$. marginale St. Maries stabilate, and ticks were applied 26 days later when the percent parasitized erythrocytes (PPE) was $0.94 \%$. Ticks acquisition fed for seven days, including during the peak of infection at 3.4\% on day 28 , then were gently removed. Ticks were held at $26^{\circ} \mathrm{C}$ in $97 \%$ humidity and 12 hours light: 12 hours dark photoperiod for seven days to allow clearance of the blood meal from the mouthparts in order to prevent mechanical transmission of $A$. marginale. Subsequently, ticks were applied to naïve 5 month old calf 41431 for a seven day transmission feed. Both calves were determined to be negative for antibodies to $A$. marginale by competitive ELISA (VMRD, Pullman, WA, USA) prior to experimental infection [34]. Cohorts of post-acquisition ticks and posttransmission ticks were dissected after a three day hold at $26^{\circ} \mathrm{C}$ in $97 \%$ humidity and 12 hours light: 12 hours dark photoperiod. Individual salivary gland pairs and midguts were collected and stored in cell lysis buffer (Gentra/ Qiagen, Valencia, CA, USA) with $200 \mu \mathrm{g} / \mathrm{mL}$ proteinase $\mathrm{K}$ for DNA extraction, and pools of 10 salivary gland pairs or midguts were stored in $200 \mu \mathrm{L}$ RNA Later (Qiagen) for RNA extraction [15]. Genomic DNA was extracted from individual tick salivary gland pairs and midguts following an overnight incubation at $56^{\circ} \mathrm{C}$ as previously described [11]. To determine pathogen load, qRT-PCR was performed using primers specific for the single copy gene msp5 [35]. RNA was extracted from tick salivary glands and midguts using Qiashredder and RNeasy (Qiagen), and then treated with TurboDNAse (Ambion) as previously described [36].

\section{Quantitative PCR}

qRT-PCR was used to confirm RNA-seq results from blood and cell culture samples and to determine transcription levels in tick samples. Complementary DNA was synthesized from total RNA using Vilo Superscript (Invitrogen). Ten genes differentially regulated according to the RNA-seq data were targeted with qRT-PCR (SybrGreen, Invitrogen), in addition to the constitutively expressed msp5 used for normalization [15,25]. Primers used in this study are shown in Table 1 . The delta delta $C t(\Delta \Delta C t)$ calculation was employed to calculate relative change [37]. Bootstrap analysis assigned significance to the fold change values based on consistency among replicates [38].

\section{Results}

Transcriptional analysis of surface protein genes

RNA from $A$. marginale in tick cell culture and bovine erythrocytes was analyzed by RNA-seq. Analysis of global transcriptional patterns showed that several of the most down regulated genes in tick cell culture corresponded to

Table 1 Oligonucleotides for qPCR

\begin{tabular}{|c|c|c|}
\hline Name & Sequence $\left(5^{\prime}-3^{\prime}\right)$ & Target gene \\
\hline AM008 F & ATGCAGCAGCGTGGAGAAGCT & AM008 \\
\hline AM008 R & AAGCTGGTCCTGTGTGGTTGTTACGT & \\
\hline AM009 F & AAGGGACGGCGAAGTCACAGC & AM009 \\
\hline AM009 R & TACTTGGACCTCAGGGTACATTTGGCT & \\
\hline AM360 F & TTGACTTACTCGCTGGTATCGCCTACAA & AM360 \\
\hline AM360 R & AAGAGTACCCAAGTATGCCAAAACCCGA & \\
\hline AM366 F & TATGGCGAGGAAGGCGTTCAAAGTC & AM366 \\
\hline AM366 R & TGCGAAGCACCGTACATGACGATT & \\
\hline AM779 F & AGGACCACAACCCCATCATGTTTGT & AM779 \\
\hline AM779 R & TTCCCTAGAGCAGAGGTCTAGTGAGT & \\
\hline Msp3 F1 (2281) & AACCCAACTTTCAACGGTATCAAGGACCT & msp3 \\
\hline Msp3 R1 (2528) & ATCCCTACTTCAACCCTGGCTCCT & \\
\hline Mspib F (229) & TACGAGAGCGTGGGACTACGTGCTA & mspib \\
\hline Msp1b R (439) & AAGCTGCTGCCTTGCCAAATTCTTG & \\
\hline New msp5 F & AAGTTGTAAGTGAGGGCATAGCCTCC & msp5 \\
\hline New msp5 R & AACTTATCGGCATGGTCGCCTAGT & \\
\hline Omp4 F & TTCCAACACACAGGAGGTGACACAC & omp4 \\
\hline Omp4 R & TTCTCTGCACCATAGCCCGCAA & \\
\hline Omp8 F & TTGCCCGAGCACCGAGATTTCT & omp8 \\
\hline Omp8 R & ATGGCTITGCGTCTCCGTTCAG & \\
\hline virB10 F & ATCGTGGACGTAAGGACATTCCCCA & virB10 \\
\hline virB10 R & TGACTGTGAGTTGGTCTAGGGTCATCC & \\
\hline
\end{tabular}


those that encoded surface proteins. Therefore, we examined genes encoding surface proteins for their transcriptional status. A. marginale has a relatively small number of known surface proteins, thus, only fifty-six single copy genes were included in the analysis based on genomic and proteomic evidence that they encode surface proteins [39]. Proteins encoded by more than one gene were eliminated from the analysis due to ambiguous mapping of sequenced reads. Fold changes were considered significant if greater than two standard deviations above or below the average fold change across all surface genes between replicates, and with a p-value below 0.01. Based on these criteria, 26 surface protein encoding genes had decreased transcription in ISE6 culture, and eight surface protein encoding genes had increased transcription (Figure 1, Table 2, Additional file 1). Analysis of relative transcription of all $A$. marginale genes in ISE6 culture compared to bovine blood indicated a similar percentage of up and down regulated genes $(20.5 \%$ and $18.6 \%$, respectively), whereas genes encoding surface proteins were generally transcribed at a lower level in tick cells (46.4\%) (Table 3).

Gene set enrichment analysis (GSEA) and custom annotation files allowed for analysis of all genes encoding surface proteins as a group. This group of genes was evaluated in the context of the other known gene categories and pathways in the $A$. marginale genome [25]. GSEA identified 14 significantly altered gene categories between $A$. marginale isolated from bovine blood and tick cell culture. The groups most significantly different $(\mathrm{p}<0.01)$ between the studied conditions included members of the Type IV Secretion System (T4SS), the pathogenesis category, and surface proteins. The latter category displayed the lowest $\mathrm{p}$-value (Table 4).

K-means clustering was used to confirm trends followed by surface protein encoding genes and to identify genes for qRT-PCR validation of RNA-seq data. Most genes (874) fell into Cluster 2, which is comprised of genes that were mostly up regulated and slightly down regulated between blood and tick cell culture conditions. Clusters 1 and 4 grouped a small number of genes, only three and one respectively. This is not surprising as they cluster the most dramatically up- and down-regulated genes. The difference in average expression values for these clusters was much greater than the differences seen in Cluster 2. Cluster 3 was of special interest as it included a total of 78 genes that were significantly down regulated in cell culture, including 15 of the surface protein encoding genes. Seven of the genes from Cluster 3 and all three genes from Cluster 1 were chosen to validate the RNA-seq data (Figure 2). Silhouette indexes were calculated for these genes in order to corroborate proximity to their own clusters. The silhouette index confirmed the trend for 9 out of 10 genes, with omp 4 not being validated by the analysis. The confidence indicator calculated for omp4 indicated that it actually belonged to Cluster 2 .

\section{Validation of RNA-seq results by qRT-PCR}

Quantitative real-time PCR (qRT-PCR) was performed on a set of ten genes differentially regulated according to the RNA-seq data (am008, am009, am360, am366, am779, msp1B1, msp3, omp4, omp8, virb10), and the constitutively expressed $m s p 5$ was used for normalization. Differential regulation shown by RNA-seq was confirmed by qRT-PCR for eight out of the ten genes examined (Table 5). The two genes whose trends were not confirmed, am366 and $a m 779$, are annotated as hypothetical and an outer membrane protein, respectively. They were down regulated in ISE6 culture according to RNA-seq analysis, but up regulated according to $\mathrm{qRT}$-PCR.

\section{qRT-PCR of $A$. marginale RNA from tick salivary glands and midguts}

In order to collect tissues representing a complete transmission cycle ticks were fed on an $A$. marginale infected calf to acquire the organism and then allowed to feed on a naïve calf to transmit the organism following typical feeding and holding times. These ticks were confirmed to be positive for $A$. marginale, with $100 \%$ infection rates and a mean infection level of $10^{5}$ organisms per salivary gland pair and midgut by qRT-PCR targeting msp5 (data not shown). RNA was extracted from salivary glands and midguts from cohorts of post-acquisition (pa) and post-

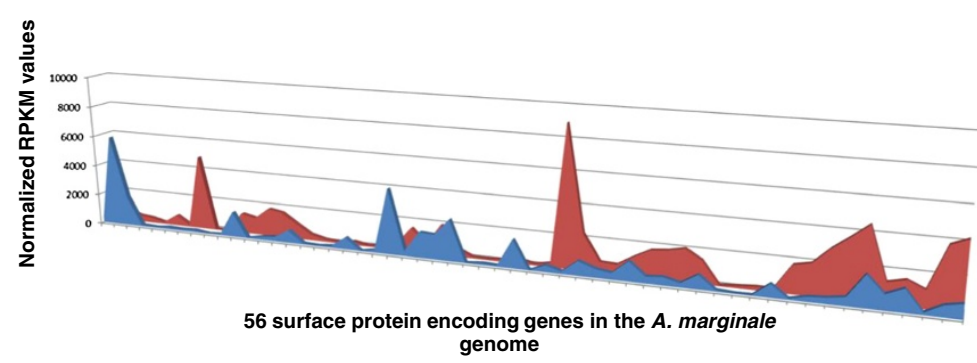

Figure 1 Whole genome comparison of $A$. marginale transcriptional activity in ISE6 cells v. blood. The normalized RPKM values for 56 surface protein encoding genes are shown on the $y$ axis. Features are arranged from left to right as they appear on the $A$. marginale chromosome on the $x$ axis. RPKM values for A. marginale transcription in ISE6 cells are shown in blue; values for transcripts in blood are shown in red. 
Table 2 Genes encoding surface proteins differentially transcribed in ISE6 culture v. blood

\begin{tabular}{|c|c|c|c|c|}
\hline Genome ID & Functional annotation & Fold change ISE6/Blood & ISE6 RPKM & Blood RPKM \\
\hline AM778 & Outer membrane protein & 9.8 & 4221.0 & 430.2 \\
\hline AM090 & MSP4 & 6.7 & 5950.9 & 891.8 \\
\hline AM956 & Cytosol aminopeptidase; pepA & 6.6 & 1827.0 & 275.6 \\
\hline AM854 & Putative peptidoglycan-associated lipoprotein & 5.0 & 2672.7 & 532.8 \\
\hline AM097 & VirB9-1 & 4.4 & 1925.6 & 434.9 \\
\hline AM197 & Undefined product & 3.9 & 54.9 & 14.2 \\
\hline AM1166 & OMP5 & 3.8 & 828.7 & 216.5 \\
\hline AM560 & Putative cell-surface protein & 3.5 & 787.4 & 226.7 \\
\hline AM1142 & OpAG2 & -3.5 & 516.0 & 1827.0 \\
\hline AM123 & MSP1b2 & -3.6 & 90.7 & 330.6 \\
\hline AM1140 & OpAG3 & -4.0 & 434.0 & 1727.4 \\
\hline AM573 & Paralog of AM560 & -4.2 & 13.5 & 56.5 \\
\hline AM878 & AAAP & -4.4 & 21.6 & 95.9 \\
\hline AM1315 & VirB9-2 & -4.7 & 898.2 & 4221.0 \\
\hline AM779 & Outer membrane protein & -4.8 & 317.5 & 1533.7 \\
\hline AM532 & MLP2 & -4.9 & 78.7 & 386.4 \\
\hline AM535 & MLP3 & -5.1 & 31.6 & 162.4 \\
\hline AM127 & Undefined product & -5.2 & 134.1 & 692.9 \\
\hline AM1159 & OMP3 & -5.4 & 23.9 & 128.6 \\
\hline AM1314 & virB10 & -5.4 & 698.9 & 3795.2 \\
\hline AM529 & Undefined product & -5.5 & 301.3 & 1648.1 \\
\hline AM1164 & OMP4 & -5.5 & 37.9 & 207.7 \\
\hline AM987 & OMP15 & -5.6 & 14.2 & 79.4 \\
\hline AM1220 & OMP7 & -6.3 & 309.9 & 1960.9 \\
\hline AM188 & Partial gene of msp1b gene family; msp1Bpg1 & -6.5 & 7.3 & 47.0 \\
\hline AM1222 & OMP9 & -7.0 & 532.2 & 3703.0 \\
\hline AM1258 & OMP13 & -7.1 & 155.7 & 1110.2 \\
\hline AM1143 & OpAG1 & -7.6 & 268.9 & 2040.0 \\
\hline AM1221 & OMP8 & -7.8 & 377.6 & 2929.1 \\
\hline AM387 & Undefined product & -8.6 & 210.2 & 1809.7 \\
\hline AM1219 & OMP6 & -22.1 & 79.4 & 1753.8 \\
\hline AM180 & MSP1b1 & -35.1 & 138.4 & 4857.2 \\
\hline AM366 & Undefined product & -46.9 & 23.2 & 1085.6 \\
\hline AM1063 & MSP3 & -55.2 & 162.8 & 8984.4 \\
\hline
\end{tabular}

transmission (pt) fed ticks. qRT-PCR targeting seven down regulated and three up regulated genes revealed surface protein gene transcription of $A$. marginale in tick cell culture mimics early infection in the tick salivary gland (Figure 3, Table 5). The three up regulated genes, according to RNA-seq, included in this analysis (am008, am009, am360) were confirmed as up regulated in all tick conditions: salivary glands post-acquisition (SGpa), salivary glands post-transmission (SGpt), midguts postacquisition (MGpa), and tick midguts post-transmission (MGpt). The tick condition most similar to ISE6 culture was the post-acquisition salivary glands in which five of the seven $A$. marginale genes tested were down regulated in SGpa in addition to ISE6 as determined by both RNA-seq and qRT-PCR. Consistent with RNA-seq data, am779 was down regulated in SGpa, while am366 was slightly up regulated, consistent with qRT-PCR data comparing ISE6 versus blood. The only gene consistently down regulated in all tick conditions was virB10. Genes down regulated in ISE6 cells according to RNA-seq were less likely to be down regulated in the following tick conditions: SGpt, MGpa and MGpt. Aside from SGpa, 
Table 3 Percentages of $A$. marginale differentially transcribed genes in ISE6 culture v. bovine blood

\begin{tabular}{lll}
\hline & All genes (952) & Surface protein-encoding genes (56) \\
\hline Increased & $195(20.5 \%)$ & $8(14.3 \%)$ \\
Decreased & $177(18.6 \%)$ & $26(46.4 \%)$ \\
Unchanged & $580(60.9 \%)$ & $22(39.3 \%)$ \\
\hline
\end{tabular}

transcription in other tick samples was dissimilar to that in ISE6 cells, indicating differences in environmental conditions may result in altered gene transcription.

\section{Discussion}

RNA-seq data revealed a disproportionate down regulation of surface protein gene transcription in tick cell culture compared to bovine blood. Additionally, GSEA analysis found the group of surface protein encoding genes to be altered, warranting a more in depth analysis of these genes. Relatively little is known about the eight surface protein encoding genes up regulated in tick cell culture, whereas the 26 down regulated surface protein encoding genes include several well-studied genes due to their immunogenicity and function. The steady-state gene, msp5, was confirmed by RNA-seq not to be differentially transcribed between the two studied conditions; the protein product for this gene has also been demonstrated to be steady state [17]. Complete sequencing of the St. Maries strain of $A$. marginale revealed that over three quarters of surface proteins belong to two superfamilies (the $m s p 2$ and $m s p 1$ superfamilies), both of which were found to be down regulated in tick cell culture in this study [40].

Members of the $m s p 2$ superfamily were generally transcribed at a lower level in tick cell culture, with the exception of $m s p 2, m s p 4$ and omp5. Lower levels of transcription in ISE6 cells were observed for several omps, opag3 and msp3, which had the lowest relative transcription of all surface proteins in A. marginale infected cell culture. Down regulation of msp 3 was confirmed by qRT-PCR, but the fold change was not as great as determined by RNA-seq. This can be explained by specificity of qRT-PCR primers for a sequence specific to the single $m s p 3$ expression site, while the RNAseq data were skewed by sequence reads from expression site variants that were not represented in the sequence used for mapping (i.e. a single $m s p 3$ sequence is represented in the expression site of the genome sequence, while the RNA-seq data were obtained from a population of organisms expressing different msp3 variants). Transcription of the immunodominant and antigenically variable $m s p 2$ was not significantly different between conditions, while all other members of the same operon (opags 1, 2, 3) were significantly down regulated in culture. It is not clear why msp 2 would behave differently from other members of its operon, but it is likely that $m s p 2$ has lower transcription in tick cell culture consistent with other members of its operon and the msp 2 homolog in A. phagocytophilum (p44) [18,40,41]. One explanation hinges on $m s p 2$ variants differing between the bovine host and the arthropod vector [20]. Msp2 variants expressed in the tick vector are known to be

Table 4 Significantly differentially transcribed A. marginale genes when comparing ISE6 v. blood with GSEA

\begin{tabular}{|c|c|c|c|c|}
\hline Category & Description & Test statistic & Lower tail $^{\mathrm{a}}$ & Upper tail $^{\mathrm{a}}$ \\
\hline 19867 & Outer membrane & -675.412 & $0^{b}$ & 1 \\
\hline 30255 & Protein secretion by the type IV secretion system (PMID:1 1895979 [TAS]) & -423.133 & $0^{b}$ & 1 \\
\hline 9405 & Pathogenesis (GO_REF:0000011 [ISS] TIGR_TIGRFAMS:TIGR02800) & -131.569 & 0.0046 & 0.9954 \\
\hline 6289 & Nucleotide-excision repair (PMID:16482227 [ISS] TIGR_TIGRFAMS:TIGR00630) & -86.7752 & 0.0155 & 0.9845 \\
\hline 8152 & Metabolic process (PMID:16482227 [ISS] UniProtKB:P28304) & -49.7659 & 0.0208 & 0.9792 \\
\hline 9253 & Peptidoglycan catabolic process (PMID:10952301 [ISS]) & -38.009 & 0.0273 & 0.9727 \\
\hline 6810 & Transport (PMID:12704232 [ISS] Pfam:PF02472) & -48.3038 & 0.0421 & 0.9579 \\
\hline 6298 & Mismatch repair (PMID:16482227 [ISS] TIGR_TIGRFAMS:TIGR01070) & -24.2468 & 0.0476 & 0.9524 \\
\hline 9089 & $\begin{array}{l}\text { Lysine biosynthetic process via diaminopimelate (GO_REF:0000011 [ISS] TIGR_TIGRFAMS: } \\
\text { TIGR00656) }\end{array}$ & 62.61262 & 0.9557 & 0.0443 \\
\hline 6556 & S-adenosylmethionine biosynthetic process (PMID:16482227 [ISS] TIGR_TIGRFAMS:TIGR01034) & 51.23363 & 0.957 & 0.043 \\
\hline 6436 & Tryptophanyl-tRNA aminoacylation (PMID:16482227 [ISS] TIGR_TIGRFAMS:TIGR00233) & 70.56015 & 0.9705 & 0.0295 \\
\hline 16114 & Terpenoid biosynthetic process (PMID:16482227 [ISS] TIGR_TIGRFAMS:TIGR00154) & 60.77005 & 0.9706 & 0.0294 \\
\hline 42255 & Ribosome assembly (PMID:16482227 [ISS] Pfam:PF00573) & $1.8 \mathrm{E}+308$ & 0.9757 & 0.0243 \\
\hline 6402 & mRNA catabolic process (PMID:16482227 [ISS] UniProtKB:P05055) & 82.09836 & 0.9873 & 0.0127 \\
\hline
\end{tabular}

a Lower/Upper tail: Lower and Upper tail values show the mass in the permutation based p-value distribution below or above the value of the test statistic.

${ }^{\mathrm{b}} \mathrm{P}$ values represented as 0 are less than $10^{-16}$ 


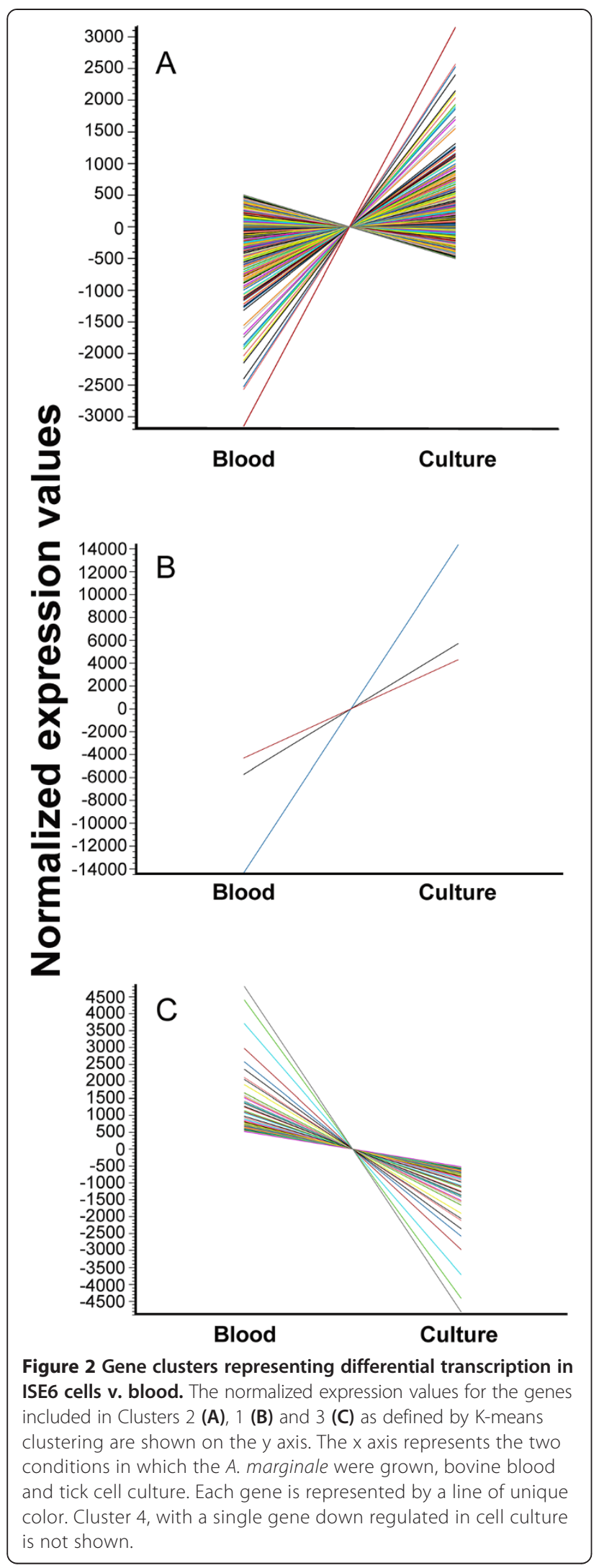

less complex than variants expressed in the bovine host, as they have been shown to incorporate segments derived from fewer donor pseudogene sequences than variants identified in blood. The lower complexity of tick expressed variants would facilitate mapping to the "simple" msp 2 expression site contained in the genome sequence. It appears that the reads from $A$. marginale infected ISE6 culture were mapped more efficiently to the $m s p 2$ expression site in the genome sequence than the reads from blood, resulting in enhancement of the reads from culture and diminution of the reads from blood. Down regulation of $m s p 2$ transcription in ISE6 culture may have been masked, and thus seen as an insignificant fold change between conditions.

Nine of the 15 genes encoding "outer membrane proteins" (OMPs) of the msp 2 superfamily were differentially transcribed, with eight having lower transcription levels in ISE6 cells compared to bovine blood. Relative transcription and expression of OMPs in bovine erythrocytes and a different tick cell line (IDE8) or tick MGs and SGs have previously been examined by immunoblotting and qRT-PCR [16]. Of the seven OMPs previously demonstrated to be down regulated in IDE8 tick cell culture, RNA-seq confirmed lower transcription levels in tick cell culture of four: omp 4, 7, 8 and 9. The remaining three previously shown to be down regulated (omp1, 10 and 11) were not differentially transcribed between ISE6 culture and bovine erythrocytes in the present experiment. Lower relative protein expression in IDE8 cells was also demonstrated in the previous study for omp 1, 4, 7, 8, 9 and 11 , while omp 10 was undetectable in both blood and IDE8 cells by immunoblotting [16]. A. phagocytophilum omp1 has been shown to be down regulated in ISE6 culture compared to a human cell line [4]. Disagreement between RNA-seq and previous studies may reside in inherent differences in techniques, cell lines used, their infection levels and interpretation criteria. Also, transcription levels of orthologs in A. phagocytophilum may not be a good indicator of transcription in A. marginale as these species have different tick vectors and vertebrate host cell tropism.

The smaller $m s p 1$ superfamily was also generally down regulated in $A$. marginale infected tick cell culture as compared to bovine erythrocytes. Four members of this six gene family were transcribed at significantly lower levels in tick cells (msp1b1, msp1b2, mlp2, mlp3), and the other two members had comparable levels of transcription in the erythrocytes versus tick cells (mspla and $m l p 4)$. These data were in contrast to previously published data that $m s p 1 b$ was transcribed and expressed at similar levels in blood and tick cells and mspla had decreased transcription and expression in tick cells compared to blood [42]. The finding that msp1b1 and $m s p 1 b 2$ are down regulated in tick cells makes sense in the context of previously demonstrated adhesion properties of $m s p 1 b$ in bovine erythrocytes, but not in tick cells 
Table 5 qPCR transcriptional fold change determination in ISE6 and tick samples v. blood

\begin{tabular}{|c|c|c|c|c|c|c|}
\hline & \multirow{2}{*}{$\frac{\text { RNA-seq }}{\text { ISE6 v Blood }}$} & \multicolumn{5}{|c|}{ qPCR } \\
\hline & & ISE6 v Blood & SGpa v Blood & SGpt v Blood & MGpa v Blood & MGpt v Blood \\
\hline $\mathrm{am} 366$ & -46.9 & 6.6 & 1.1 & 18.5 & 10.9 & -4.4 \\
\hline am779 & -4.8 & 2.6 & -2.3 & -1.3 & 1.1 & 1.7 \\
\hline msp1b & -35.1 & -8.3 & -5.9 & 1.5 & -9.6 & -1.2 \\
\hline msp3 & -55.2 & -4.5 & -15.0 & 1.4 & 1.1 & -7.3 \\
\hline omp4 & -5.5 & -7.1 & -3.8 & -53.7 & 1.2 & 3.3 \\
\hline omp8 & -7.8 & -1.8 & -1.4 & 1.8 & 2.2 & 2.9 \\
\hline virb10 & -5.4 & -6.9 & -16.0 & -4.9 & -1.3 & -4.1 \\
\hline am008 & 61.0 & 14.4 & 138.8 & 25.5 & 19.4 & 78.1 \\
\hline am009 & 303.0 & 10.1 & 8.0 & 26.1 & 8.5 & 127.4 \\
\hline am360 & 8655.0 & 34.6 & 13.1 & 1.9 & 84.2 & 4.2 \\
\hline
\end{tabular}

[43]. Additionally, mspla which has adhesin properties in both bovine erythrocytes and tick cells was not differentially transcribed [43].

Two members of the T4SS, virB9-2 and virB10, were transcribed at a lower level in tick cell culture, while a third T4SS member, virB9-1, was up regulated. The T4SS has a role in effector translocation, and virB9-1, virB9-2 and virB10 are components of the core T4SS complex that forms a secretory channel between the bacterium's inner and outer membranes [44]. Immunoprecipitation studies have shown that VirB9-2 and VirB10 both interact with VirB9-1, but not each other, suggesting that VirB9-1 is a central part of the structure forming the core complex of the T4SS [45]. Down and up regulation of virB9-2 and virB9-1 are of approximately equal magnitude, -4.7 and 4.4 fold change, respectively. Alternate transcription of virB9-1 and virB9-2 in ticks versus the host may indicate a functional change in the T4SS in the two environments. The trend of down regulation was confirmed for virB10 in all tick samples studied, indicating consistent down regulation in tick tissues through all stages of infection. GSEA further confirmed this observation as the category composed of T4SS genes was one of the most significantly altered. Because a specific antibody response is mounted against virB9-1, virB9-2 and virB10 in outer membrane-vaccinated and naturally infected calves, they have been targeted in vaccine studies which showed broad $\mathrm{MCH}$ class II presentation and interactions which enhance their immunogenicity if used as a linked protein vaccine [45-48]. In contrast to the findings of this study, tiling arrays have previously shown increased transcription of A. phagocytophilum T4SS genes in ISE6 culture as compared to mammalian cell lines, once again indicating that A. phagocytophilum transcription is a poor indicator of transcription in A. marginale [4].

The Anaplasma appendage-associated protein (AAAP) was also transcribed at a lower level in A. marginale infected culture compared to blood. A role for AAAP in both blood and ticks is expected as F-actin appendages are assembled on the cytoplasmic surface of $A$. marginale

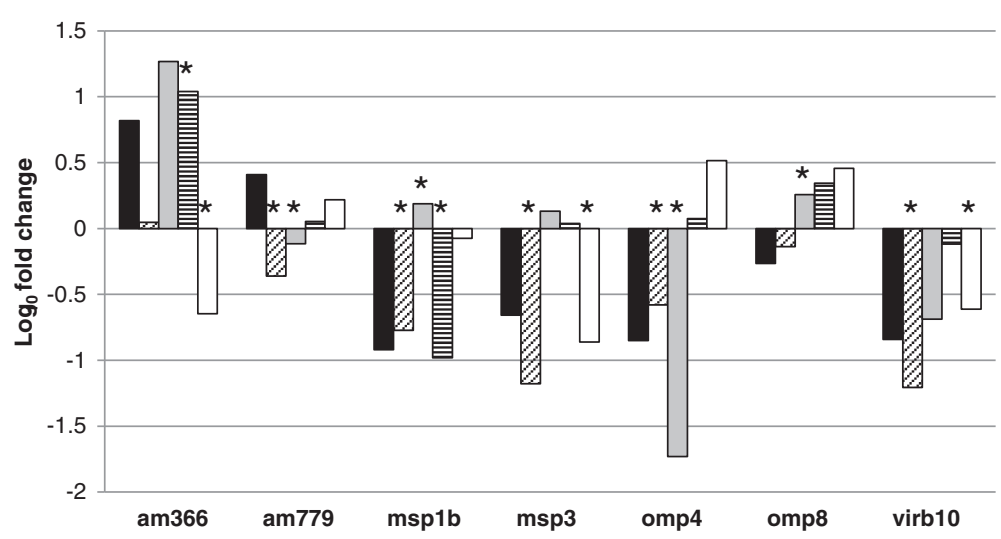

Figure 3 qPCR transcriptional fold change determination in ISE6 and tick samples v. blood. Graphical representation of seven cell surface protein encoding genes' transcriptional fold change in tick samples versus bovine blood as determined by qRT-PCR. ISE6 is represented by black bars, SGpa by bars containing diagonal stripes, SGpt by gray bars, MGpa by bars containing horizontal stripes and MGpt by white bars. Bootstrap analysis assigned significance ${ }^{*}$ ) to the fold change values based on consistency among replicates. 
containing vacuoles within erythrocytes and appendages are associated with $A$. marginale in the tick blood meal and tick midgut $[49,50]$. Variation in expression levels between strains has been demonstrated, so it is possible that our finding is strain-specific [49].

Previous characterization of the A. marginale proteome between the bovine host and vector identified AM778 to be expressed only in the tick $[17,51]$. Consistent with previous studies, RNA-seq found am778 to be the most highly up regulated surface protein in ISE6 cells. Distantly related paralogs, AM779 and AM780, have been identified in protein complexes from A. marginale in blood, but not in ISE6 culture [51]. RNA-seq supported this previous observation by showing am779 and am780 to be down regulated in ISE6 culture, however, the fold change of am780 was not considered significant by the parameters set for this study. Down regulation of am779 in ISE6 cells was not confirmed by qRT-PCR. AM779 has been examined as a subdominant antigen, but did not provide protective immunity against challenge in immunized animals [52]. The RNA-seq data suggests alternative transcription of $a m 778$ and $a m 779$ in tick cells and erythrocytes, respectively, similar to $\operatorname{sp} A$ and ospC of Borrelia burgdorferi.

While tools have advanced such that global transcriptional analyses are now possible for obligate intracellular organisms, it is important to keep in mind that transcription does not necessarily reflect the dynamics of protein expression. The strategy used in this study allows for a genome wide identification of differentially transcribed targets between the different conditions, however, the expression status of the encoded proteins needs to be corroborated before testing them as transmission blocking candidates. Post-transcriptional and post-translational regulation may explain discrepancies between transcript and protein data. For example, relative expression of several non-surface protein encoding genes from $A$. marginale have been studied in the bovine host versus vector environments, and previous protein expression data are not always congruent with the transcriptional data presented here. Specifically, a previous study showed that AnkC was exclusively expressed in ISE6 cells [53], while in our study transcription was decreased in ISE6 cells as compared to bovine blood. In the same study, higher expression of AnkA was observed in erythrocytes, but RNA-seq data showed no difference between transcription levels of ankA in the two conditions [53]. Furthermore, protein expression of AM470, AM410 and AM829 was higher in tick cells compared to blood, but only am829 was transcribed at higher levels in tick cells [17]. Both am470 and am410 had equal transcription in the two conditions. Therefore, RNA-seq may be a reliable measurement of relative transcript abundance, but may not reflect protein expression.

\section{Conclusions}

Deep sequencing technology has provided a comprehensive data set allowing global transcriptional analysis of $A$. marginale genes in the tick vector compared to bovine blood. Surface proteins were disproportionately down regulated in tick cell culture, and quantitative PCR confirmed this trend in post-acquisition tick salivary glands for a set of genes. Transcription of A. marginale genes in other tick samples was dissimilar to that in ISE6 cells, indicating differences in environmental conditions may result in differences in gene transcription patterns. Significant remodeling of the $A$. marginale surface in the tick vector may represent a survival strategy, a response to the lack of specific immune pressure, and evidence of specific protein functions not required in the tick. ISE6 culture is shown here to most closely mimic A. marginale gene transcription in the tick salivary gland environment following acquisition feeding.

\section{Additional file}

\section{Additional file 1: Whole genome transcriptional profiling of $A$. marginale from ISE6 cell culture or blood. The genome wide transcriptional comparison is reported. Fold changes, total gene reads, raw and normalized expression values, and p-values for Kal's test are shown.}

\section{Competing interests}

The authors declare that they have no competing interests.

\section{Authors' contributions}

GKH, SAP, GAS, KAB conceived the experiments; GKH, SAP, XC performed the experiments; GKH, SAP, XC, KAB analyzed the data; GKH, SAP and KAB wrote and edited the manuscript. All authors read and approved the final manuscript.

\section{Acknowledgements}

We are grateful for the technical expertise of Ralph Horn and James Allison. This work was supported by USDA CREES NRI CGP 2005-35604-15440, and National Institutes of Health Grant Al44005. GKH was a trainee under NIH T32-Al0070 Immunology Training Grant. SAP was supported in part by fellowships from the Poncin Trust and CONACYT.

\section{Author details}

${ }^{1}$ Program in Genomics, Department of Veterinary Microbiology and Pathology, Paul G. Allen School for Global Animal Health, Washington State University, Pullman, WA 99164-7040, USA. ${ }^{2}$ Animal Disease Research Unit, U.S. Department of Agriculture, Agricultural Research Service, PO Box 646630, Pullman, WA 99164-6630, USA. ${ }^{3}$ Present address: Department of Comparative Pathobiology, Purdue University, West Lafayette, IN 47907, USA.

Received: 28 January 2014 Accepted: 8 April 2014

Published: 21 April 2014

\section{References}

1. Kuriakose JA, Miyashiro S, Luo T, Zhu B, McBride JW: Ehrlichia chaffeensis transcriptome in mammalian and arthropod hosts reveals differential gene expression and post transcriptional regulation. PLoS One 2011 6:e24136.

2. Schwan TG, Piesman J: Temporal changes in outer surface proteins $A$ and $\mathrm{C}$ of the lyme disease-associated spirochete, Borrelia burgdorferi, during the chain of infection in ticks and mice. J Clin Microbiol 2000, 38:382-388.

3. Gilmore RD Jr, Mbow ML, Stevenson B: Analysis of Borrelia burgdorferi gene expression during life cycle phases of the tick vector Ixodes scapularis. Microbes Infect 2001, 3:799-808. 
4. Nelson CM, Herron MJ, Felsheim RF, Schloeder BR, Grindle SM, Chavez AO, Kurtti TJ, Munderloh UG: Whole genome transcription profiling of Anaplasma phagocytophilum in human and tick host cells by tiling array analysis. BMC Genomics 2008, 9:364.

5. Kocan KM, Stiller D, Goff WL, Claypool PL, Edwards W, Ewing SA, McGuire TC, Hair JA, Barron SJ: Development of Anaplasma marginale in male Dermacentor andersoni transferred from parasitemic to susceptible cattle. Am J Vet Res 1992, 53:499-507.

6. Kocan KM: Development of Anaplasma marginale in ixodid ticks: coordinated development of a rickettsial organism and its tick host. In Morphology, physiology, and behavioral biology of ticks. Edited by Hair JRSaJA. England: Ellis Horwood, Ltd; 1986:472-505.

7. de la Fuente J, Garcia-Garcia JC, Blouin EF, McEwen BR, Clawson D, Kocan KM: Major surface protein 1a effects tick infection and transmission of Anaplasma marginale. Int J Parasitol 2001, 31:1705-1714.

8. Blouin EF, Saliki JT, de la Fuente J, Garcia-Garcia JC, Kocan KM: Antibodies to Anaplasma marginale major surface proteins $1 \mathrm{a}$ and $1 \mathrm{~b}$ inhibit infectivity for cultured tick cells. Vet Parasitol 2003, 111:247-260.

9. McGarey DJ, Barbet AF, Palmer GH, McGuire TC, Allred DR: Putative adhesins of Anaplasma marginale: major surface polypeptides 1a and 1b. Infect Immun 1994, 62:4594-4601.

10. Kocan KM, Goff WL, Stiller D, Claypool PL, Edwards W, Ewing SA, Hair JA, Barron SJ: Persistence of Anaplasma marginale (Rickettsiales: Anaplasmataceae) in male Dermacentor andersoni (Acari: Ixodidae) transferred successively from infected to susceptible calves. J Med Entomol 1992, 29:657-668.

11. Lohr CV, Rurangirwa FR, McElwain TF, Stiller D, Palmer GH: Specific expression of Anaplasma marginale major surface protein 2 salivary gland variants occurs in the midgut and is an early event during tick transmission. Infect Immun 2002, 70:114-120.

12. Kocan KM, Holbert D, Edwards W, Ewing SA, Barron SJ, Hair JA: Longevity of colonies of Anaplasma marginale in midgut epithelial cells of Dermacentor andersoni. Am J Vet Res 1986, 47:1657-1661.

13. Munderloh UG, Liu Y, Wang M, Chen C, Kurtti TJ: Establishment, maintenance and description of cell lines from the tick Ixodes scapularis. J Parasitol 1994, 80:533-543.

14. Munderloh UG, Blouin EF, Kocan KM, Ge NL, Edwards WL, Kurtti TJ: Establishment of the tick (Acari:Ixodidae)-borne cattle pathogen Anaplasma marginale (Rickettsiales:Anaplasmataceae) in tick cell culture. J Med Entomol 1996, 33:656-664.

15. Agnes JT, Herndon D, Ueti MW, Ramabu SS, Evans M, Brayton KA, Palmer GH: Association of pathogen strain-specific gene transcription and transmission efficiency phenotype of Anaplasma marginale. Infect Immun 2010, 78:2446-2453.

16. Noh SM, Brayton KA, Knowles DP, Agnes JT, Dark MJ, Brown WC, Baszler TV, Palmer GH: Differential expression and sequence conservation of the Anaplasma marginale msp2 gene superfamily outer membrane proteins. Infect Immun 2006, 74:3471-3479.

17. Ramabu SS, Ueti MW, Brayton KA, Baszler TV, Palmer GH: Identification of Anaplasma marginale proteins specifically upregulated during colonization of the tick vector. Infect Immun 2010, 78:3047-3052.

18. Lohr CV, Brayton KA, Shkap V, Molad T, Barbet AF, Brown WC, Palmer GH: Expression of Anaplasma marginale major surface protein 2 operon-associated proteins during mammalian and arthropod infection. Infect Immun 2002, 70:6005-6012.

19. Garcia-Garcia JC, de la Fuente J, Bell-Eunice G, Blouin EF, Kocan KM: Glycosylation of Anaplasma marginale major surface protein 1a and its putative role in adhesion to tick cells. Infect Immun 2004, 72:3022-3030.

20. Chavez AS, Felsheim RF, Kurtti TJ, Ku PS, Brayton KA, Munderloh UG: Expression patterns of Anaplasma marginale Msp2 variants change in response to growth in cattle, and tick cells versus mammalian cells. PLoS One 2012, 7:e36012.

21. Pierle SA, Dark MJ, Dahmen D, Palmer GH, Brayton KA: Comparative genomics and transcriptomics of trait-gene association. BMC Genomics 2012, 13:669.

22. Albrecht M, Sharma CM, Reinhardt R, Vogel J, Rudel T: Deep sequencing-based discovery of the Chlamydia trachomatis transcriptome. Nucleic Acids Res 2010, 38:868-877.

23. Martin J, Zhu W, Passalacqua KD, Bergman N, Borodovsky M: Bacillus anthracis genome organization in light of whole transcriptome sequencing. BMC Bioinforma 2010, 11(Suppl 3):S10.
24. Felsheim RF, Chavez AS, Palmer GH, Crosby L, Barbet AF, Kurtti TJ, Munderloh UG: Transformation of Anaplasma marginale. Vet Parasitol 2010, 167:167-174.

25. Pierle SA, Hammac GK, Palmer GH, Brayton KA: Transcriptional pathways associated with the slow growth phenotype of transformed Anaplasma marginale. BMC Genomics 2013, 14:272.

26. Mortazavi A, Williams BA, McCue K, Schaeffer L, Wold B: Mapping and quantifying mammalian transcriptomes by RNA-Seq. Nat Methods 2008, 5:621-628.

27. Kal AJ, van Zonneveld AJ, Benes V, van den Berg M, Koerkamp MG, Albermann K, Strack N, Ruijter JM, Richter A, Dujon B, Ansorge W, Tabak HF: Dynamics of gene expression revealed by comparison of serial analysis of gene expression transcript profiles from yeast grown on two different carbon sources. Mol Biol Cell 1999, 10:1859-1872.

28. Yang IV, Chen E, Hasseman JP, Liang W, Frank BC, Wang S, Sharov V, Saeed Al, White J, Li J, Lee NH, Yeatman TJ, Quackenbush J: Within the fold: assessing differential expression measures and reproducibility in microarray assays. Genome Biol 2002, 3:research0062.

29. Tian L, Greenberg SA, Kong SW, Altschuler J, Kohane IS, Park PJ: Discovering statistically significant pathways in expression profiling studies. Proc Natl Acad Sci U S A 2005, 102:13544-13549.

30. Lloyd S: Least squares quantization in PCM. IEEE Trans Inf Theory 1982, 28:129-137.

31. Dalton $L$, Ballarin V, Brun M: Clustering algorithms: on learning, validation, performance, and applications to genomics. Curr Genomics 2009, 10:430-445.

32. Eriks IS, Stiller D, Palmer GH: Impact of persistent Anaplasma marginale rickettsemia on tick infection and transmission. J Clin Microbiol 1993, 31:2091-2096

33. Scoles GA, Broce AB, Lysyk TJ, Palmer GH: Relative efficiency of biological transmission of Anaplasma marginale (Rickettsiales: Anaplasmataceae) by Dermacentor andersoni (Acari: Ixodidae) compared with mechanical transmission by Stomoxys calcitrans (Diptera: Muscidae). J Med Entomol 2005, 42:668-675.

34. Knowles D, Torioni de Echaide S, Palmer G, McGuire T, Stiller D, McElwain T: Antibody against an Anaplasma marginale MSP5 epitope common to tick and erythrocyte stages identifies persistently infected cattle. J Clin Microbiol 1996, 34:2225-2230.

35. Hammac GK, Ku PS, Galletti MF, Noh SM, Scoles GA, Palmer GH, Brayton KA: Protective immunity induced by immunization with a live, cultured Anaplasma marginale strain. Vaccine 2013, 31:3617-3622.

36. Agnes JT, Brayton KA, LaFollett M, Norimine J, Brown WC, Palmer GH: Identification of Anaplasma marginale outer membrane protein antigens conserved between $A$. marginale sensu stricto strains and the live $A$. marginale subsp. centrale vaccine. Infect Immun 2010, 79:1311-1318.

37. Livak KJ, Schmittgen TD: Analysis of relative gene expression data using real-time quantitative PCR and the 2(-Delta Delta C(T)) Method. Methods 2001, 25:402-408.

38. Cleries R, Galvez J, Espino M, Ribes J, Nunes V, de Heredia ML: BootstRatio: a web-based statistical analysis of fold-change in qPCR and RT-qPCR data using resampling methods. Comput Biol Med 2012, 42:438-445.

39. Brayton KA, Palmer GH, Brown WC: Genomic and proteomic approaches to vaccine candidate identification for Anaplasma marginale. Expert Rev Vaccines 2006, 5:95-101.

40. Brayton KA, Kappmeyer LS, Herndon DR, Dark MJ, Tibbals DL, Palmer GH, McGuire TC, Knowles DP Jr: Complete genome sequencing of Anaplasma marginale reveals that the surface is skewed to two superfamilies of outer membrane proteins. Proc Natl Acad Sci U S A 2005, 102:844-849.

41. Wang X, Cheng Z, Zhang C, Kikuchi T, Rikihisa Y: Anaplasma phagocytophilum p44 mRNA expression is differentially regulated in mammalian and tick host cells: involvement of the DNA binding protein ApxR. J Bacteriol 2007, 189:8651-8659.

42. Garcia-Garcia JC, de la Fuente J, Blouin EF, Johnson TJ, Halbur T, Onet VC, Saliki JT, Kocan KM: Differential expression of the msplalpha gene of Anaplasma marginale occurs in bovine erythrocytes and tick cells. Vet Microbiol 2004, 98:261-272.

43. Kocan KM, De La Fuente J, Blouin EF, Garcia-Garcia JC: Adaptations of the tick-borne pathogen, Anaplasma marginale, for survival in cattle and ticks. Exp Appl Acarol 2002, 28:9-25.

44. Gillespie JJ, Brayton KA, Williams KP, Diaz MA, Brown WC, Azad AF, Sobral BW: Phylogenomics reveals a diverse Rickettsiales type IV secretion system. Infect Immun 2010, 78:1809-1823. 
45. Morse K, Norimine J, Palmer GH, Sutten EL, Baszler TV, Brown WC: Association and evidence for linked recognition of type IV secretion system proteins VirB9-1, VirB9-2, and VirB10 in Anaplasma marginale. Infect Immun 2012, 80:215-227.

46. Araujo FR, Costa CM, Ramos CA, Farias TA, Souza II, Melo ES, Elisei C, Rosinha GM, Soares CO, Fragoso SP, Fonseca AH: IgG and IgG2 antibodies from cattle naturally infected with Anaplasma marginale recognize the recombinant vaccine candidate antigens VirB9, VirB10, and elongation factor-Tu. Mem Inst Oswaldo Cruz 2008, 103:186-190.

47. Lopez JE, Palmer GH, Brayton KA, Dark MJ, Leach SE, Brown WC: Immunogenicity of Anaplasma marginale type IV secretion system proteins in a protective outer membrane vaccine. Infect Immun 2007, 75:2333-2342

48. Morse K, Norimine J, Hope JC, Brown WC: Breadth of the CD4+ T cell response to Anaplasma marginale VirB9-1, VirB9-2 and VirB10 and MHC class II DR and DQ restriction elements. Immunogenetics 2012, 64:507-523.

49. Stich RW, Olah GA, Brayton KA, Brown WC, Fechheimer M, Green-Church K, Jittapalapong S, Kocan KM, McGuire TC, Rurangirwa FR, Palmer GH: Identification of a novel Anaplasma marginale appendage-associated protein that localizes with actin filaments during intraerythrocytic infection. Infect Immun 2004 72:7257-7264.

50. Kocan KM, Ewing SA, Hair JA, Barron SJ: Demonstration of the inclusion appendage of Anaplasma marginale in nymphal Dermacentor andersoni. Am J Vet Res 1984, 45:1800-1807.

51. Noh SM, Brayton KA, Brown WC, Norimine J, Munske GR, Davitt CM, Palmer GH: Composition of the surface proteome of Anaplasma marginale and its role in protective immunity induced by outer membrane immunization. Infect Immun 2008, 76:2219-2226.

52. Albarrak SM, Brown WC, Noh SM, Reif KE, Scoles GA, Turse JE, Norimine J, Ueti MW, Palmer GH: Subdominant antigens in bacterial vaccines: AM779 is subdominant in the Anaplasma marginale outer membrane vaccine but does not associate with protective immunity. PLoS One 2012, 7:e46372.

53. Ramabu SS, Schneider DA, Brayton KA, Ueti MW, Graca T, Futse JE, Noh SM, Baszler TV, Palmer GH: Expression of Anaplasma marginale ankyrin repeat-containing proteins during infection of the mammalian host and tick vector. Infect Immun 2011, 79:2847-2855.

doi:10.1186/1756-3305-7-193

Cite this article as: Hammac et al:: Global transcriptional analysis reveals surface remodeling of Anaplasma marginale in the tick vector. Parasites \& Vectors 2014 7:193.

\section{Submit your next manuscript to BioMed Central and take full advantage of:}

- Convenient online submission

- Thorough peer review

- No space constraints or color figure charges

- Immediate publication on acceptance

- Inclusion in PubMed, CAS, Scopus and Google Scholar

- Research which is freely available for redistribution 